\title{
Short or long end of the lever? Associations between provider communication of the "asthma-action plan" and outpatient revisits for pediatric asthma
}

\author{
Pavani Rangachari ${ }^{* 1}$, Renuka Mehta ${ }^{2}$, R. Karl Rethemeyer ${ }^{3}$, Carole Ferrang $^{4}$, Clifton Dennis ${ }^{5}$, Vickie Redd ${ }^{4}$ \\ ${ }^{1}$ Department of Health Management \& Informatics, Georgia Regents University, Augusta, Georgia, United States \\ ${ }^{2}$ Department of Pediatrics, Georgia Regents University, Augusta, Georgia, United States \\ ${ }^{3}$ Department of Public Administration \& Policy, University at Albany, State University of New York, United States \\ ${ }^{4}$ Children's Hospital of Georgia, Georgia Regents Medical Center, Augusta, Georgia, United States \\ ${ }^{5}$ CSRA Asthma Coalition, Georgia Regents University, Augusta, Georgia, United States
}

Received: April 28, 2015

DOI: $10.5430 /$ jha.v4n5p26
Accepted: June 7, 2015

URL: http://dx.doi.org/10.5430/jha.v4n5p26

\begin{abstract}
Objective: At the Children's Hospital of Georgia (CHOG), we found that outpatient revisits for pediatric asthma were significantly above national norms. According to the NIH, costly hospital revisits for asthma can be prevented through guidelines-based self-management of asthma, central to which, is the use of a written Asthma-Action Plan (AAP). The asthma services literature has emphasized the role of the healthcare provider in promoting asthma self-management using the AAP, to prevent hospital revisits. On the other hand, the asthma policy literature has emphasized the need for a community-based approach to promote asthma self-management. A gap remains in understanding the extent of leverage that healthcare providers may have in preventing hospital revisits for asthma, through effective communication of AAP in the outpatient setting. Our study sought to address this gap.

Methods: We conducted a 6-month intervention to implement patient-and-family-centered communication of the AAP in CHOG outpatient clinics, based on the "change-management" theoretical framework. Provider communication of AAP was assessed through a survey of "Parent Understanding of the Child's AAP". A quasi-experimental approach was used to measure outpatient revisits for pediatric asthma, pre- and post-intervention.

Results: Survey results showed that provider communication of the AAP was unanimously perceived highly positively by parents of pediatric asthma patients, across various metrics of patient-and-family-centered care. However, there were no statistically significant differences in outpatient "revisit behavior" for pediatric asthma between pre- and post-intervention periods after controlling for several demographic variables. Additionally, revisits remained significantly above national norms.

Conclusions: The study suggests that effective provider communication of the AAP by itself, may have limited potential to reduce hospital outpatient revisits for pediatric asthma. Results indicate the need for a broader community-based approach to address patient life variables impacting self-management and hospital revisits for pediatric asthma. Findings suggest need for a revised "socio-ecological" theoretical framework, and also provide insight into various research and practice implications for asthma management and control.
\end{abstract}

Key Words: Pediatric asthma, Patient-and-family-centered communication, Asthma self-management, Change management, Community-based interventions, Socio-ecological framework

*Correspondence: Pavani Rangachari; Email: prangachari@gru.edu; Address: Department of Health Management \& Informatics, College of Allied Health Sciences, Georgia Regents University, Augusta, GA 30912, United States. 


\section{INTRODUCTION}

Asthma is an inflammatory disorder of the lungs that affects over 43 million Americans of all ages. It is associated with enormous healthcare expenditures that include both direct and indirect costs. The direct costs of asthma, an estimated total of $\$ 56$ billion per year in the U.S., include inpatient care, emergency room (ER) visits, outpatient clinic visits, nursing services, drugs and devices, and blood and diagnostic tests. ${ }^{[1]}$ While inpatient hospitalizations and ER visits are known to be major contributors to the direct cost of asthma, some studies have identified outpatient clinic visits to be the largest expense of asthma, accounting for $55 \%-58 \%$ of direct costs. ${ }^{[2,3]}$

According to the National Institutes of Health (NIH) National Asthma Education and Prevention Program (NAEPP), costly asthma symptoms, including hospital admissions and multiple visits to the ER or outpatient clinics can often be prevented with guidelines-based asthma care and appropriate self-management of asthma. Correspondingly, the 2007 NAEPP Expert Panel Report (EPR-3) has emphasized the importance of patient education for asthma control. ${ }^{[4]} \mathrm{A}$ central component of asthma self-management education is the "Asthma-Action Plan (AAP)", a written step-by-step plan that explains what medicines to take and when to take them; what environmental triggers to avoid; how to handle signs and symptoms of worsening asthma; and what to do during an asthma episode, to enable asthma control. The purpose of the AAP is to incorporate the individual patient into the plan of care, and address how to appropriately treat one's asthma. The AAP should be developed jointly by the healthcare provider and the patient, and represent a providerpatient partnership that emphasizes education and educationreinforcement, to encourage self-management of asthma. ${ }^{[4-6]}$ Since 2007, hospitals across the U.S. have been encouraged by the Joint Commission and other agencies to ensure that all asthma patients are provided with a written AAP (regardless of setting). In 2008, The Joint Commission announced the first pediatric core measure set on Child Asthma Care, which includes a measure of pediatric asthma patients discharged with the AAP. ${ }^{[7]}$

Therefore, implicit in the NAEPP guidelines, is a hierarchy of "desirability" attached to the asthma healthcare utilization spectrum, with: 1) self-management of asthma being considered "most desirable" (from the perspectives of both healthcare expenditures and health status), followed by 2) outpatient clinic visits, 3) ER visits, and 4) inpatient hospital admissions, the latter of which is considered "least desirable". The NAEPP guidelines are further reinforced by the asthma services literature, which underscores the importance of "patient-and-family centered communication of the AAP" in promoting self-management of asthma. ${ }^{[6,8,9]}$ Correspondingly, both the national guidelines and the asthma services literature have emphasized the role of the healthcare provider in promoting self-management of asthma (through use of the AAP) to prevent multiple hospital encounters for asthma.

On the other hand however, the asthma policy literature has emphasized the need for: 1) asthma self-management education in community settings, and 2) changes in asthma reimbursement policy to promote a community-based approach to asthma self-management. ${ }^{[1,10]}$ For example, the Community Preventive Services Task Force, an independent body of public health and prevention experts, suggests "home-based multi-trigger, multicomponent interventions with an environmental focus for children with asthma, based on evidence of effectiveness in improving overall quality of life and productivity". [10]

Correspondingly, there is a gap in the literature with respect to understanding the extent of "leverage" that healthcare providers may have in promoting self-management and reducing hospital encounters for asthma, through effective communication of the AAP in the hospital setting. Addressing this gap may be crucial in determining the optimal role of healthcare providers in asthma management and control. For example, if in fact the evidence suggests that efforts to improve provider communication of the AAP in the hospital setting may be the "long-end of the lever", with significant potential for reducing hospital encounters for asthma, then healthcare providers and managers may wish to focus their efforts on "perfecting" provider communication of the AAP in the hospital setting. Besides, it could be a relatively inexpensive and cost-effective way for hospitals to give back to the community, and mitigate the costly community health burden of asthma. This study seeks to address this gap in the literature.

\subsection{Purpose}

The CHOG, located in the Central Savannah River Area (Augusta, GA), records a total of approximately 5,000 "noninpatient" visits for pediatric asthma (i.e., 0-17 year age group) per year, including ER visits, outpatient clinic visits, observation cases, ambulatory surgery center visits, and miscellaneous non-inpatient visits. An analysis of the University Health Consortium (UHC) national comparative database revealed statistically significant differences between CHOG and national peer group averages with respect to the proportion of ER visits and outpatient clinic visits for pediatric asthma.

As shown in Table 1, between July 2011 and June 2014 
(i.e., "three-year" period), ER visits as a proportion of total non-inpatient visits for pediatric asthma at CHOG (15\%), was significantly lower than the corresponding national peergroup average of $46 \%$ (Chi-Sq. $>3.84 ; p<.001$ ). However, during the same timeframe, outpatient clinic visits as a proportion of total non-inpatient visits for pediatric asthma at CHOG (80\%), was significantly higher than its corresponding national peer-group average of $19 \%$ (Chi-Sq. > 3.84; $p<.0001)$. In summary, while the data showed a lower proportion of ER visits for pediatric asthma at CHOG compared to the national average, the significantly higher proportion of outpatient visits for pediatric asthma compared to the national average, suggested considerable scope for improving self-management of pediatric asthma, and reducing outpatient visits for pediatric asthma at $\mathrm{CHOG}$.

Table 1. Assessment of differences in ER \& clinic visits for pediatric asthma: CHOG vs. National (FY 2012 - FY 2014$)$

\begin{tabular}{|c|c|c|c|c|c|c|}
\hline & & CHOG & $\begin{array}{l}\begin{array}{l}\text { National } \\
\text { (Comparative Peer-Group) }\end{array} \\
\end{array}$ & $\begin{array}{l}\text { Chi-Square } \\
\text { Value } \\
\end{array}$ & $\begin{array}{l}\text { Critical } \\
\text { Value } \\
\end{array}$ & $p$-value \\
\hline \multirow{3}{*}{$\begin{array}{l}\text { ER visits as a } \\
\text { proportion of total } \\
\text { non-inpatient } \\
\text { visits }\end{array}$} & $\begin{array}{l}\text { Three consecutive years } \\
\text { (July } 2011 \text { to June 2014) }\end{array}$ & $\begin{array}{l}15 \% \\
(2,173 / 14,074)\end{array}$ & $\begin{array}{l}46 \% \\
(126,369 / 274,128)\end{array}$ & 5,091 & $\geq 3.84$ & $<.001$ \\
\hline & $\begin{array}{l}\text { Two consecutive years } \\
\text { (July } 2011 \text { to June 2013) }\end{array}$ & $\begin{array}{l}18 \% \\
(1,472 / 8,333)\end{array}$ & $\begin{array}{l}49 \% \\
(84,628 / 171,412)\end{array}$ & 3,200 & $\geq 3.84$ & $<.001$ \\
\hline & $\begin{array}{l}\text { One year } \\
\text { (July } 2013 \text { to June 2014) }\end{array}$ & $\begin{array}{l}12 \% \\
(701 / 5,741)\end{array}$ & $\begin{array}{l}41 \% \\
(41,741 / 102,716)\end{array}$ & 1,843 & $\geq 3.84$ & $<.001$ \\
\hline \multirow{3}{*}{$\begin{array}{l}\text { Clinic visits as a } \\
\text { proportion of total } \\
\text { non-inpatient } \\
\text { visits }\end{array}$} & $\begin{array}{l}\text { Three consecutive years } \\
\text { (July } 2011 \text { to June 2014) }\end{array}$ & $\begin{array}{l}80 \% \\
(11,230 / 14,074)\end{array}$ & $\begin{array}{l}19 \% \\
(51,849 / 274,128)\end{array}$ & 29,016 & $\geq 3.84$ & $<.0001$ \\
\hline & $\begin{array}{l}\text { Two consecutive years } \\
\text { (July } 2011 \text { to June 2013) }\end{array}$ & $\begin{array}{l}77 \% \\
(6,443 / 8,333)\end{array}$ & $\begin{array}{l}16 \% \\
(27,847 / 171,412)\end{array}$ & 19,196 & $\geq 3.84$ & $<.0001$ \\
\hline & $\begin{array}{l}\text { One year } \\
\text { (July } 2013 \text { to June 2014) }\end{array}$ & $\begin{array}{l}83 \% \\
(4,787 / 5,741)\end{array}$ & $\begin{array}{l}23 \% \\
(24,002 / 102,716)\end{array}$ & 10,040 & $\geq 3.84$ & $<.0001$ \\
\hline
\end{tabular}

A deeper assessment of $\mathrm{CHOG}$ asthma encounters served to reinforce this concern. The data revealed that over a 6-month period, "revisits" (or multiple visits) to outpatient clinics for pediatric asthma, outnumbered unique patient visits by over 200\%. To elaborate, between July and December 2012, CHOG recorded 1,227 unique patient visits for outpatient asthma care (based on "Patient ID"). However, when we tracked each patient for a 6-month window after their initial visit to determine if they revisited the outpatient (or any other part of the facility) even once, we found a total of 2,468 "revisits" for this population. Additionally, the data revealed that 562 (46\%) of these individuals revisited CHOG for pediatric asthma outpatient care two or more times, and $353(30 \%)$ revisited three or more (multiple) times (see Figure 1).

These findings related to higher-than-expected revisits for pediatric asthma outpatient care at $\mathrm{CHOG}$, were consistent with published statistics indicating significantly higher prevalence rates of child asthma in the Georgia (GA) vs. U.S. (i.e., 11\% in GA compared to $5.7 \%$ in U.S. for children aged 0-4 years), and the highest prevalence rates for child asthma in Augusta, GA $(>9 \%)$ compared to other regions in GA. ${ }^{[11,12]}$ In 2011, the Asthma and Allergy Foundation of America named Augusta, GA in the "Top Ten Asthma Capitals of the U.S.", and in 2013, Augusta, GA was reported by the NBC corporation to be "among the worst cities in the U.S. for asthma". In summary, both the hospital data and regional/statewide statistics on child asthma prevalence suggested considerable scope for reducing outpatient clinic revisits for pediatric asthma at CHOG, by promoting self-management (or home care) of asthma.

As discussed earlier, both the NAEPP guidelines and the asthma services literature have emphasized the role of the healthcare provider in promoting self-management of asthma through effective (patient-and-family centered) communication of the AAP. Following from this literature, we sought to evaluate the leverage of "effective provider-to-patient/family communication of the AAP", in reducing outpatient revisits for pediatric asthma, at CHOG. Our efforts began with a review of "evidence-based practices" for ensuring patientand-family-centered communication of AAP. The literatures on "health literacy" and "patient-and-family-centered care" were particularly informative in this regard; providing insight into a broad set of best practices (outlined below) for ensuring effective patient-and-family centered communication of the AAP by providers: 1) provide a written AAP that is easy to read and understand; 2$)$ explain the AAP in simple $\left(5^{\text {th }}\right.$ grade) English; 3) ask patients to repeat treatment instructions (teach-back); 4) ask patients to demonstrate medication use (teach-back); and 5) provide patients with the opportu- 
nity to ask questions and share their concerns. ${ }^{[13-16]}$ Armed with this information, we sought to conduct an "intervention" to implement patient-and-family-centered communication (and ensure effective patient/family understanding) of the AAP at CHOG. We then used a "quasi-experimental" approach to measure outpatient revisits for pediatric asthma, pre- and post-intervention. The remaining portion of this paper discusses the theoretical rationale, methods, results, and implications of the study.

\subsection{Intervention}

Our intervention involved implementing a "patient-andfamily centered approach" to communicating the AAP to parents of pediatric asthma patients at CHOG. The intervention lasted six months, and consisted of two main components:

(1) A six-month survey of "parent understanding of the child's AAP", administered to parents of pediatric asthma patients (in outpatient and inpatient settings at $\mathrm{CHOG})$, by the very providers who were responsible for communicating the AAP to parents;

(2) Concerted efforts by asthma care providers at $\mathrm{CHOG}$ (i.e., physicians, nurses, respiratory therapists, and Certified Asthma Educators) to revise and simplify the written AAP (based on best practices), immediately prior to launch of the survey, accompanied by conscious efforts to improve providers' oral communication practices related to the AAP immediately before and throughout the survey period.

Following IRB approvals, the survey of "parent understanding of the child's AAP" was conducted over a 6-month period (between July and December 2013), in outpatient and inpatient settings at $\mathrm{CHOG}$. The one-page survey was designed to capture information on three areas: 1) Patient/child demographic characteristics; 2) Parent assessment of provider communication of the child's AAP on a variety of patientand-family-centered care metrics; and 3) Parental reports of their own self-efficacy in adhering to the AAP. The surveys were distributed to parents at discharge by the very providers who were responsible for communicating the child's AAP to parents. Parents in turn, were requested to drop off their completed surveys in designated locked drop-off boxes, before leaving the hospital. As such, providers knew they were being observed, and correspondingly, the potential for the survey to influence provider behavior through the "Hawthorne Effect" (i.e., the tendency to perform better when being observed), must be acknowledged. ${ }^{[17]}$

Prior to the survey, several pediatric asthma providers involved in the study (i.e., physicians, nurses, and respiratory

Published by Sciedu Press therapists), felt that the written AAP being used at the time was difficult for to parents to understand, since it was not written in plain English. As such, providers leveraged the opportunity provided by the preparation-time for the survey to revise and simplify the written AAP, based on best-practices obtained from the literature. Concurrently, providers undertook conscious efforts to refine their oral communication practices related to AAP through educational in-service and group discussions of encounters with parents/families of child asthma patients. These efforts persisted throughout the survey period. In summary, prior to launch of the survey, providers at $\mathrm{CHOG}$ undertook concerted efforts to maximize their efficacy as communicators in the context of AAP. As such, providers also viewed the survey as an opportunity to gain systematic feedback from parents regarding their understanding of the child's AAP. The revised AAP went into effect approximately two weeks prior to launch of the survey.

The theoretical rationale for our intervention emanates from the literature on implementing and sustaining change in healthcare organizations (i.e., "change-management framework"), which in turn, owes its roots to the broader, copious literature on complexity and "Professional Complex Systems (PCS)". The PCS framework suggests that during times of change, proactive and periodic communication and observation efforts from senior hospital leaders/administrators may be necessary to enable tacit knowledge exchanges across provider subgroups (i.e., insight and discussion related to work practices), collective learning, and behavior/practice change. ${ }^{[18-20]}$ Several successful change initiatives in healthcare organizations have utilized the PCS framework to create a period of intense observation, communication and knowledge exchange, to in turn enable collective learning and behavior/practice change, particularly in the context of implementing evidence-based practices, e.g., for preventing catheter-related bloodstream infections. ${ }^{[21-24]}$ This intervention uses a similar approach to implementing change in the context of evidence-based practices related to provider-topatient/family communication of the AAP.

To evaluate intervention impact, we closely examined outpatient clinic visit and revisit behavior for pediatric asthma during the 6-month intervention period, i.e., from 07/01/13 to $12 / 31 / 13$; and as a comparison, we examined outpatient clinic visit and revisit behavior for pediatric asthma in the corresponding timeframe during the previous year, i.e., from 07/01/12 to $12 / 31 / 12$.

Our strong expectation based on the literature, was that if the intervention mattered at all, it should help to reduce revisits; On the other hand, if in fact the survey revealed a highly positive perception of provider communication of the 
AAP (by parents), while the level of outpatient revisits for pediatric asthma remained unchanged (or increased) from the corresponding previous period, and also remained significantly above national norms; then it could help to at least rule out inefficacious provider communication (or the lack of parent understanding) of the AAP, as an explanation for higher-than-expected outpatient revisits for pediatric asthma at CHOG. At the same time, such results would suggest limited potential for "effective provider communication of the AAP" to reduce outpatient revisits for pediatric asthma, thereby providing a basis for investigating other factors that may impacting self-management of asthma and hospital revisits at the patient's end (instead of the hospital provider's end). Such insights could in turn set the stage for future research to understand the "root causes" of hospital revisits for pediatric asthma.

\section{MeTHODS}

We used a "quasi-experimental" approach to compare broad performance on outpatient clinic visits and revisits for pediatric asthma at $\mathrm{CHOG}$ before and after our 6-month intervention, i.e., $07 / 01 / 13$ to $12 / 31 / 13$. Our primary data source for hospital visits (including outpatient clinic visits) for pediatric asthma, was the UHC administrative database for the CHOG for the period July 1, 2012 to June 30, 2014. Pediatric asthma visits were identified using ICD-9 principal diagnosis codes for asthma in the 0-17 year patient age group. In addition to ICD-9 diagnosis codes, the database included medical record numbers (i.e., individual patient IDs) and encounter IDs, which in turn helped capture revisits or multiple visits for asthma by the same patient. Additionally, the database contained information on a variety of patient demographic characteristics, including age, sex, race/ethnicity, insurance (payer), admission source, and discharge status.

To determine our intervention group, we identified patients who appeared for outpatient care for asthma at least once between $07 / 01 / 13$ to $12 / 31 / 13$ (i.e., the survey period). We then followed each patient for a 6-month window after their initial visit to determine if they revisited the outpatient (or any other part of the facility, i.e., CHOG), even once. To determine our control group, we identified patients who appeared for outpatient care for asthma at least once during the corresponding period in the previous year, i.e., between $07 / 01 / 12$ to $12 / 31 / 12$. We then followed each patient for a 6-month window after their initial visit to determine if they revisited the outpatient (or any other part of the facility, i.e., CHOG), even once.

As such, a "revisit" was defined as returning to the outpatient clinic (or any other part of the facility) for pediatric asthma (based on principal diagnosis) even once, within 6 months of an initial visit to the outpatient clinic (during the intervention or control period, as the case may be). We conducted a variety of significance tests to assess differences in demographic characteristics between the intervention and control groups. Concurrently, we conducted a variety of multivariate regression analyses to assess systematic differences between the intervention and control groups in whether or not there were hospital "revisits" for pediatric asthma.

\section{RESULTS}

\subsection{Results from survey of "parent understanding of child's AAP'}

We received a total of 412 responses to the survey over the six-month period (i.e., 7/1/2013 to 12/31/2013) from outpatient and inpatient settings at CHOG. Of these, $289(70 \%)$ were from outpatient clinics; 123 (30\%) surveys were from inpatient areas. Table 2 summarizes results for "all respondents," i.e., from outpatient and inpatient settings $(\mathrm{n}=412)$, and for "outpatient respondents only" $(n=289)$. Results are divided into three sections: 1) Demographic characteristics; 2) Parent assessment of provider communication of child's AAP; and 3) Parental report of self-efficacy in adhering to the AAP.

As indicated under "Demographics" (see Table 2), a majority of survey respondents in both categories (i.e., "all respondents" and "outpatient-only respondents") were parents/caregivers of elementary school age, male, AfricanAmerican children on Medicaid insurance. Nearly $90 \%$ of parents/caregivers (in both categories) indicated having an education level of high school or higher; and over $50 \%$ in both categories indicated a household income of below $\$ 25,000$. Also, a majority of survey respondents (nearly $65 \%$ in both categories) characterized their child's asthma as "intermittent" or "mild", and approximately $20 \%$ in both categories characterized it as "moderate". Correspondingly, asthma severity in the survey population may best be characterized as "low-to-moderate severity". As shown under "Parent Assessment of Provider Communication of AAP" (see Table 2), the survey revealed an overwhelmingly positive perception of provider communication of AAP by parents, across a variety of "patient-and-family-centered care metrics" (in both categories, i.e., "all-outpatient and inpatient respondents" and "outpatient only respondents"). For example, over 95\% of parents in both categories, responded in the affirmative to "was AAP explained in a way you could understand?" and "Did you get a chance to ask all questions?" Over 95\% of parents also responded in the affirmative to "Did you receive a Written AAP?" and "Was the AAP easy to read and understand?" Over $80 \%$ of parents in both categories responded in the affirmative to both the "teach-back" metrics: 
"Were you asked to give medicines to your child?" and "Were you asked to repeat treatment instructions?" The survey revealed similar results under "parental self-efficacy in caring for child's asthma" with overwhelmingly positive reports of self-efficacy across all metrics (see Table 2). Over $90 \%$ of parents responded in the affirmative for "I can prevent a future asthma attack in my child by adhering to AAP" and over $95 \%$ responded affirmatively to "I can help my child during asthma attack", and "I know which medicines my child should take daily" or "when the child is getting worse".

Table 2. Parent understanding of AAP (July 12013 - December 31, 2013)

\begin{tabular}{|c|c|c|}
\hline Metric & All: Outpatient \& Inpatient $(n=412)$ & Outpatient Only $(n=289)$ \\
\hline \multicolumn{3}{|l|}{ I. Demographics } \\
\hline Average age of patient (child) & 8.5 years & 9.1 years \\
\hline School grade of patient (child) & 53\% (Elementary) & 55\% (Elementary) \\
\hline Gender of patient (child) & 60\% (Male) & 58\% (Male) \\
\hline Race of patient (child) & 70\% (African-American) & 69\% (African-American) \\
\hline Insurance of patient (child) & 61\% (Medicaid) & 58\% (Medicaid) \\
\hline Asthma severity of patient (child) & 64\% (Intermittent or Mild) & $66 \%$ (Intermittent or Mild) \\
\hline Household income & 55\% (Below \$25,000/year) & 52\% (Below \$25,000/year) \\
\hline Primary caregiver & 62\% (Mom) & 63\% (Mom) \\
\hline Caregiver education & 90\% (High school or higher) & 89\% (High school or higher) \\
\hline Caregiver employment & 57\% (Employed) & 55\% (Employed) \\
\hline \multicolumn{3}{|c|}{ II. Parent assessment of provider communication of Asthma-Action Plan } \\
\hline Who talked with you about child's asthma? & 75\% (physician) & 77\% (physician) \\
\hline Received written asthma-action plan (AAP)? & $95 \%$ (yes) & $96 \%$ (Yes) \\
\hline AAP easy to read and understand? & $97 \%$ (yes) & $96 \%$ (Yes) \\
\hline Was AAP explained in a way you could understand? & $98 \%$ (yes) & $97 \%$ (Yes) \\
\hline Were you asked to give medicines to your child? & 85\% (yes) & $84 \%$ (yes) \\
\hline Were you asked to repeat treatment instructions? & $81 \%$ (yes) & $82 \%$ (yes) \\
\hline Did you get a chance to ask all your questions? & $99 \%$ (yes) & $99 \%$ (Yes) \\
\hline \multicolumn{3}{|l|}{ III. Parental self-efficacy in adhering to Asthma-Action Plan } \\
\hline I can prevent future attack by adhering to the Asthma-Action Plan. & 92\% (strongly agree or agree) & $92 \%$ (strongly agree or agree) \\
\hline I can help my child during an asthma attack. & 96\% (strongly agree or agree) & $96 \%$ (strongly agree or agree) \\
\hline I know which medicines my child should take daily. & 97\% (strongly agree or agree) & 99\% (strongly agree or agree) \\
\hline I know which medicines to give when child is getting worse. & 98\% (strongly agree or agree) & $98 \%$ (strongly agree or agree) \\
\hline I understand when to call the doctor or 911. & 98\% (strongly agree or agree) & 99\% (strongly agree or agree) \\
\hline
\end{tabular}

\subsection{Results of analysis of revisits}

The control group (07/01/2012-12/31/2012) consisted of 1,227 members, i.e., unique patient visits to CHOG outpatient clinics for pediatric asthma, based on Patient ID. However, when we tracked each patient over a 6-month timeframe after their initial visit to determine if they revisited the outpatient (or any other part of the facility, i.e., CHOG) even once, we found that there were a total of 2,468 "revisits" among control group members. All revisits for pediatric asthma were to CHOG outpatient clinics. Similarly, our intervention group (07/01/2013-12/31/2013) consisted of 1,225 members, i.e., unique patient visits based on Patient ID. However, when tracked each patient over a 6-month timeframe after their ini- tial visit to determine if they revisited the outpatient (or any other part of the facility, i.e., CHOG) even once, we found that there were a total of 2,861 "revisits" among intervention group members. Again, all revisits were to CHOG outpatient clinics.

\subsubsection{Results of significance testing on demographic char- acteristics}

We conducted a variety of significance tests (two sample $t$-tests) to assess differences between the control group and the intervention group in terms of age, sex, race, insurance (payer), and asthma diagnosis type. Results are summarized in Table 3. As indicated in the table, the two samples (i.e., control group and intervention group) are indistinguishable 
from one another on all demographic characteristics, except for asthma diagnosis type. Two asthma principal diagnosis codes dominated the entire dataset, i.e., "Asthma-Extrinsic $(49,390)$ " or allergic asthma and "Asthma-NOS $(49,300)$ ", or non-allergic asthma. $T$-test results showed that the intervention group had a significantly higher proportion of Asthma-Extrinsic and a significantly lower proportion of Asthma-NOS, compared to the control group. Statistically speaking therefore, the control and intervention groups were similar to one another in all measurable demographic characteristics, except for the difference in "asthma diagnosis type". Correspondingly, we ensured the inclusion of "asthma diagnosis type" as a control variable in our multivariate analysis of systematic differences in revisits between control and intervention groups.

Table 3. Assessment of differences in demographic characteristics between intervention \& control groups

\begin{tabular}{|c|c|c|c|c|c|c|c|c|}
\hline $\begin{array}{l}\text { Demographic } \\
\text { Variable }\end{array}$ & Group & $\mathbf{N}$ & Mean & $S D$ & \multicolumn{2}{|c|}{ 95\% C.I. } & $t$ & $\begin{array}{l}\text { Significance } \\
\text { (p-value) }\end{array}$ \\
\hline \multirow{2}{*}{ Age } & Control group & 1,227 & 7.77 & 4.45 & 7.52 & 8.02 & \multirow{2}{*}{1.2699} & \multirow{2}{*}{.204} \\
\hline & Intervention group & 1,225 & 7.54 & 4.41 & 7.28 & 7.29 & & \\
\hline \multirow{2}{*}{ Gender (Female) } & Control group & 1,227 & 0.37 & 0.48 & 0.35 & 0.41 & \multirow{2}{*}{-0.1147} & \multirow{2}{*}{.908} \\
\hline & Intervention group & 1,225 & 0.38 & 0.48 & 0.35 & 0.41 & & \\
\hline \multirow{2}{*}{$\begin{array}{l}\text { Race } \\
\text { (African-American) }\end{array}$} & Control group & 1,227 & 0.64 & 0.48 & 0.61 & 0.66 & \multirow{2}{*}{-1.1073} & \multirow{2}{*}{.268} \\
\hline & Intervention group & 1,225 & 0.65 & 0.47 & 0.63 & 0.68 & & \\
\hline \multirow{2}{*}{ Race (Caucasian) } & Control group & 1,227 & 0.29 & 0.45 & 0.26 & 0.31 & \multirow{2}{*}{0.9216} & \multirow{2}{*}{.356} \\
\hline & Intervention group & 1,225 & 0.27 & 0.44 & 0.24 & 0.29 & & \\
\hline \multirow{2}{*}{ Race (Hispanic) } & Control group & 1,227 & 0.03 & 0.18 & 0.23 & 0.43 & \multirow{2}{*}{0.3401} & \multirow{2}{*}{.733} \\
\hline & Intervention group & 1,225 & 0.03 & 0.17 & 0.21 & 0.39 & & \\
\hline \multirow{2}{*}{ Insurance (Private) } & Control group & 1,227 & 0.17 & 0.38 & 0.15 & 0.19 & \multirow{2}{*}{0.4147} & \multirow{2}{*}{.678} \\
\hline & Intervention group & 1,225 & 0.16 & 0.37 & 0.14 & 0.18 & & \\
\hline \multirow{2}{*}{$\begin{array}{l}\text { Insurance (Medicaid } \\
\text { Traditional) }\end{array}$} & Control group & 1,227 & 0.27 & 0.45 & 0.25 & 0.29 & \multirow{2}{*}{0.1571} & \multirow{2}{*}{.875} \\
\hline & Intervention group & 1,225 & 0.27 & 0.44 & 0.24 & 0.29 & & \\
\hline \multirow{2}{*}{$\begin{array}{l}\text { Insurance (Medicaid } \\
\text { Managed Care) }\end{array}$} & Control group & 1,227 & 0.43 & 0.49 & 0.41 & 0.46 & \multirow{2}{*}{-0.5645} & \multirow{2}{*}{.572} \\
\hline & Intervention group & 1,225 & 0.44 & 0.49 & 0.41 & 0.47 & & \\
\hline \multirow{2}{*}{ Insurance (Military) } & Control group & 1,227 & 0.06 & 0.25 & 0.55 & 0.83 & \multirow{2}{*}{-0.4033} & \multirow{2}{*}{.686} \\
\hline & Intervention group & 1,225 & 0.07 & 0.26 & 0.58 & 0.88 & & \\
\hline \multirow{2}{*}{ Insurance (Other) } & Control group & 1,227 & 0.05 & 0.23 & 0.04 & 0.06 & \multirow{2}{*}{0.7221} & \multirow{2}{*}{.471} \\
\hline & Intervention group & 1,225 & 0.05 & 0.21 & 0.04 & 0.06 & & \\
\hline \multirow{2}{*}{$\begin{array}{l}\text { Diagnosis Type } \\
\text { (Asthma Extrinsic) }\end{array}$} & Control group & 1,227 & 0.35 & 0.48 & 0.32 & 0.38 & -8 0916 & 000 \\
\hline & Intervention group & 1,225 & 0.51 & 0.51 & 0.48 & 0.53 & -0.0710 & .000 \\
\hline Diagnosis Type & Control group & 1,227 & 0.56 & 0.49 & 0.53 & 0.58 & 84956 & 000 \\
\hline (Asthma NOS) & Intervention group & 1,225 & 0.38 & 0.48 & 0.36 & 0.41 & 0.4530 & .000 \\
\hline
\end{tabular}

\subsubsection{Results of multivariate regression analysis of system- atic differences in revisits}

Three types of regression models (described below) were constructed to examine differences in revisit behavior (for pediatric asthma care) between the control group and the intervention group.

MODEL 1: A Logistic Regression (Logit) model was used to assess systematic differences between the intervention and control groups in whether or not there were any revisits (i.e., propensity for revisits). The dichotomous Dependent Variable (DV) "any revisit" was coded " 1 " if a patient who originally visited the outpatient clinic for pediatric asthma care (during the control period or intervention period) re- turned to the clinic (or any part of the CHOG facility) for pediatric asthma care at least once in the six months following the original visit. If not, "any revisit" was coded " 0 ".

MODEL 2: A Linear Regression (OLS) model was used to assess if there was a systematic difference between the intervention and control groups in total revisits (i.e., the total number of times patients returned for pediatric asthma care over six months following the original outpatient clinic visit during the control or intervention period, as the case may be). Correspondingly, the DV "total revisits", was a count variable, and the model sought to understand if the total number of revisits was a function of being in the intervention or 
control groups, after controlling for other factors.

MODEL 3: A Logistic Regression (Logit) model was used to assess if there was a systematic difference between the intervention and control groups in whether or not there were high revisits. In this case, the dichotomous DV "high revisit" was coded " 1 " if the total number of revisits for a patient who originally visited the outpatient clinic for pediatric asthma care was $\geq 3$. If not, the DV "high revisit" was coded "0". Three revisits served as a cutoff because less than one-third of the patient population in both control and intervention groups had 3 or more revisits. A majority (over two-thirds) of both groups had 2 or less revisits.

All three regression models included the same control variables obtained from the UHC administrative database, i.e., age, gender, insurance type, race/ethnicity, asthma diagnosis type, and weekend admissions. Age was the only continuous control variable in all three models. All other control variables were dichotomous or categorical, with an omitted value providing the basis for comparison against the included values. For example, for "gender", the omitted value was "male". For "insurance", the omitted value was "Medicaid Traditional". For "race", the omitted value was "AfricanAmerican", and for "asthma principal diagnosis type", the omitted variable was "Asthma-NOS". Robust standard errors were used to correct for heteroskedasticity.

The results of all three regression models are summarized in Table 4 . The main result was that there were no statistically significant differences between the intervention and control groups in any of the three models at the $95 \%$ confidence interval level (i.e., $p<.05$ ). In other words, the coefficient for "intervention group" was not significant at the threshold of $p<.05$ in any of the three models. However, Models 1 and 2 showed significance at the $90 \%$ Confidence Interval (i.e., $p<.10$ ), with the intervention group showing a higher likelihood of revisits ("any revisit") and a higher number of revisits ("total revisits") compared to the control group. Model 3 ("high revisits") showed no statistical significance even at the $90 \%$ Confidence Interval threshold.

In summary, the regression analysis revealed no differences between the intervention and control groups in propensity for or number of revisits (at the standard 95\% Confidence Interval). If anything, revisits were higher in the intervention group, compared to the control group (at the $90 \%$ Confidence Interval). It would be relevant to note at this juncture, that the "R-Square", i.e., the proportion of variation in the DV ("revisits") explained by the model, was $\leq 3 \%$ for all three models, suggesting that none of the "measurable" patient demographic variables included in the model (i.e., age, gender, race, or insurance), had significant potential to predict revisit behavior for pediatric asthma outpatient care in the $\mathrm{CHOG}$ community.

\subsubsection{Comparison of "revisit distribution" in control and intervention groups}

Figure 1 provides a graphical representation of the revisit distribution the control and intervention groups. In essence, the figure indicates similar patterns of revisits between both groups; which in turn corroborates findings from regression analysis of no statistically significant differences between control and intervention groups in revisit behavior for pediatric asthma outpatient care.

Table 4. Assessment of systematic differences in revisit behavior between intervention \& control groups

\begin{tabular}{|c|c|c|c|c|}
\hline \multirow{2}{*}{ Varieties } & & Any Revisit & $\begin{array}{l}\text { Total } \\
\text { Revisits }\end{array}$ & $\begin{array}{l}\text { High } \\
\text { Revisits }\end{array}$ \\
\hline & & $\begin{array}{l}\text { (Logisitic } \\
\text { Regression) }\end{array}$ & $\begin{array}{l}\text { (Linear/OLS } \\
\text { Regression) }\end{array}$ & $\begin{array}{l}\text { (Logisitic } \\
\text { Regression) }\end{array}$ \\
\hline $\begin{array}{l}\text { Intervention } \\
\text { Group }\end{array}$ & $\begin{array}{l}\text { Coef. } \\
\text { (Robust SE) }\end{array}$ & $\begin{array}{l}0.167 \\
(0.094)^{\ddagger}\end{array}$ & $\begin{array}{l}0.224 \\
(0.131)^{\ddagger}\end{array}$ & $\begin{array}{l}0.153 \\
(0.107)\end{array}$ \\
\hline Age & $\begin{array}{l}\text { Coef. } \\
\text { (Robust SE) }\end{array}$ & $\begin{array}{l}-0.051 \\
(0.011)^{*}\end{array}$ & $\begin{array}{l}-0.019 \\
(0.013)\end{array}$ & $\begin{array}{l}-0.226 \\
(0.012)^{*}\end{array}$ \\
\hline $\begin{array}{l}\text { Gender } \\
\text { (Female) }\end{array}$ & $\begin{array}{l}\text { Coef. } \\
\text { (Robust SE) }\end{array}$ & $\begin{array}{l}-0.03 \\
(0.096)\end{array}$ & $\begin{array}{l}-0.194 \\
(0.133)\end{array}$ & $\begin{array}{l}-0.226 \\
(0.112)^{*}\end{array}$ \\
\hline $\begin{array}{l}\text { Comm. } \\
\text { Insurance }\end{array}$ & $\begin{array}{l}\text { Coef. } \\
\text { (Robust SE) }\end{array}$ & $\begin{array}{l}0.556 \\
(0.151)^{*}\end{array}$ & $\begin{array}{l}-0.448 \\
(0.155)^{*}\end{array}$ & $\begin{array}{l}-0.194 \\
(0.173)\end{array}$ \\
\hline $\begin{array}{l}\text { Medicaid } \\
\text { Managed Care }\end{array}$ & $\begin{array}{l}\text { Coef. } \\
\text { (Robust SE) }\end{array}$ & $\begin{array}{l}-0.635 \\
(0.118)^{*}\end{array}$ & $\begin{array}{l}-0.112 \\
(0.158)\end{array}$ & $\begin{array}{l}-0.059 \\
(0.127)\end{array}$ \\
\hline $\begin{array}{l}\text { Military } \\
\text { Insurance }\end{array}$ & $\begin{array}{l}\text { Coef. } \\
\text { (Robust SE) }\end{array}$ & $\begin{array}{l}-0.085 \\
(0.212)\end{array}$ & $\begin{array}{l}-0.403 \\
(0.164)\end{array}$ & $\begin{array}{l}-0.208 \\
(0.234)\end{array}$ \\
\hline $\begin{array}{l}\text { Other } \\
\text { Insurance }\end{array}$ & $\begin{array}{l}\text { Coef. } \\
\text { (Robust SE) }\end{array}$ & $\begin{array}{l}-0.416 \\
(0.228)^{\ddagger}\end{array}$ & $\begin{array}{l}0.088 \\
(0.402)\end{array}$ & $\begin{array}{l}0.054 \\
(0.249)\end{array}$ \\
\hline Caucasian & $\begin{array}{l}\text { Coef. } \\
\text { (Robust SE) }\end{array}$ & $\begin{array}{l}0.002 \\
(0.111)\end{array}$ & $\begin{array}{l}-0.134 \\
(0.137)\end{array}$ & $\begin{array}{l}-0.261 \\
(0.129)^{*}\end{array}$ \\
\hline Hispanic & $\begin{array}{l}\text { Coef. } \\
\text { (Robust SE) }\end{array}$ & $\begin{array}{l}0.196 \\
(0.276)\end{array}$ & $\begin{array}{l}0.361 \\
(0.371)\end{array}$ & $\begin{array}{l}0.268 \\
(0.276)\end{array}$ \\
\hline Other Race & $\begin{array}{l}\text { Coef. } \\
\text { (Robust SE) }\end{array}$ & $\begin{array}{l}-0.563 \\
(0.203)^{*}\end{array}$ & $\begin{array}{l}-0.547 \\
(0.195)^{*}\end{array}$ & $\begin{array}{l}-0.507 \\
(0.289)^{\ddagger}\end{array}$ \\
\hline $\begin{array}{l}\text { Asthma - } \\
\text { Extrinsic }\end{array}$ & $\begin{array}{l}\text { Coef. } \\
\text { (Robust SE) }\end{array}$ & $\begin{array}{l}0.392 \\
(0.103)^{*}\end{array}$ & $\begin{array}{l}0.587 \\
(0.134)^{*}\end{array}$ & $\begin{array}{l}0.298 \\
(0.113)^{*}\end{array}$ \\
\hline $\begin{array}{l}\text { Asthma - } \\
\text { Other }\end{array}$ & $\begin{array}{l}\text { Coef. } \\
\text { (Robust SE) }\end{array}$ & $\begin{array}{l}-0.342 \\
(0.155)^{*}\end{array}$ & $\begin{array}{l}0.132 \\
(0.258)\end{array}$ & $\begin{array}{l}-0.116 \\
(0.201)\end{array}$ \\
\hline $\begin{array}{l}\text { Weekend } \\
\text { Admission }\end{array}$ & $\begin{array}{l}\text { Coef. } \\
\text { (Robust SE) }\end{array}$ & $\begin{array}{l}-0.202 \\
(0.497)\end{array}$ & $\begin{array}{l}0.346 \\
(0.639)\end{array}$ & $\begin{array}{l}1.097 \\
(0.527)^{*}\end{array}$ \\
\hline $\begin{array}{l}\mathrm{N} \\
\text { (Observations) }\end{array}$ & & 2,452 & 2,452 & 2,452 \\
\hline R-Square & & 0.0327 & 0.0171 & 0.0151 \\
\hline
\end{tabular}

Note. Robust Standard Errors in Parentheses; ${ }^{\ddagger} p$-value $<.10$ (90\% Confidence Interval); ${ }^{*} p$-value $<.05$ (95\% Confidence Interval)

\subsection{Summary of results}

In summary, results from the "survey of parent understanding of child's AAP" (during the 6-month intervention period in 2013) showed that provider communication related to the AAP at CHOG, was unanimously perceived highly positively (near-perfect) by parents of pediatric asthma patients across all metrics of patient-and-family-centered care, in outpatient and inpatient settings. Concurrently, parental re- 
ports of self-efficacy in caring for the child's asthma were unanimously high (near-perfect) across outpatient and inpatient settings. Importantly however, there were no statistically significant differences (at the standard 95\% Confidence Interval) in "revisit behavior" for pediatric asthma outpatient care between the control (2012) and intervention (2013) groups, including the frequency, propensity, and pattern of revisits, while controlling for various demographic characteristics, including age, gender, race/ethnicity, insurance, and asthma diagnosis type. Additionally, outpatient clinic revisits for pediatric asthma care as a proportion of total noninpatient visits at CHOG in 2013-14 (83\%) remained significantly above the national average of $23 \%$ (Chi-sq. $>3.84$; $p<.0001)$. In summary, revisits for pediatric asthma outpatient care at $\mathrm{CHOG}$ remained unchanged between pre-and post-intervention periods, and significantly above national norms.

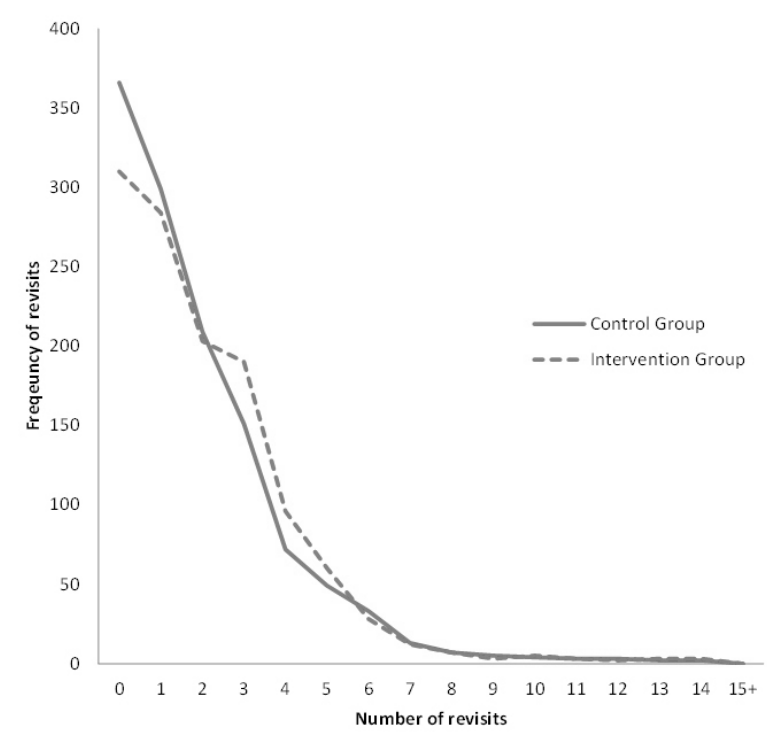

Figure 1. Graph of revisit distribution

In effect, results suggest that effective provider-topatient/family communication of the AAP in the hospital outpatient setting, by itself may not have significant potential to impact self-management and hospital revisits for pediatric asthma. In other words, efforts to improve provider communication of the AAP in the hospital setting by itself may only be the "short-end of the lever", with low leverage for impacting hospital revisits for pediatric asthma. Since self-management of asthma requires effort from both the provider and the patient, results point to the importance of understanding patient-level variables (including social, community, health system, and environmental factors impacting self-management at the patient's end), to better understand the challenge of self-management, and reduce the problem of hospital revisits. Overall, the study provides a foundation for conducting important future research on key barriers to asthma self-management and "root causes" for hospital revisits in the Augusta, GA community. Such research in turn, could serve as springboard for designing effective interventions to address the growing costs and public health burden of the disease at statewide and national levels.

At this juncture, we must acknowledge a limitation of the survey, in that it did not contain individual respondent identifiers to link the survey response to the actual revisit outcome. This limited our ability to distinguish survey results among "non-revisits", "revisits", and "high revisits" groups of patients/parents. However several features of the study and survey results serve to mitigate this limitation. To begin with, there was negligible variation in survey results with respect to both parent assessment of provider communication on AAP and parental self-efficacy in caring for the child's asthma, with the results in both areas being unanimously highly positive in across outpatient and inpatient settings. We also had large numbers of survey responses from the outpatient setting $(\mathrm{n}=289)$ and from outpatient and inpatient settings put together $(n=412)$, both of which exceeded the rule of thumb for a statistically significant sample size i.e., $\geq 30$ cases. ${ }^{[25]}$ This fetched us an outpatient survey response rate of $25 \%$, i.e., 289 out of 1,225 unique outpatient encounters for pediatric asthma between 07/01/2013 to $12 / 31 / 2013$. Moreover, there was very limited variation in demographic characteristics of survey respondents, with a vast majority being elementary school age male AfricanAmerican children on Medicaid insurance. This distribution of survey respondents also mirrored the distribution of the larger control and intervention groups analyzed for revisits. This in turn suggests limited scope for significant variation in survey results (parent understanding of child's AAP), across "non-revisits", "revisits", and "high-revisits" groups, based on demographic characteristics.

\section{Discussion}

Results ultimately suggest that focusing primarily on the outpatient provider's side of the equation (to promote adherence to the AAP) may not be an effective approach for addressing the challenge of asthma self-management and/or hospital revisits for pediatric asthma. Instead, findings point to the importance of focusing on the patient's side, because a key insight gained from the study is that there may be a vast gap between parent understanding of the AAP and their adherence to the AAP; and further investigation into reasons for this gap could shed light on "root causes" of outpatient revisits for pediatric asthma.

Parent adherence to the AAP/self-management plan in 
turn, could be influenced by numerous factors, not entirely within parents' control, including socio-economic constraints, which might be preventing patients from having prescription medications filled in a timely manner. Given that over $50 \%$ of CHOG asthma survey respondents/parents reported a household income of below $\$ 25,000$, it is possible that some may not be able to afford co-payments for inhaled corticosteroids and other long term control medicines, needed to keep asthma attacks at bay. Additionally, adherence to the AAP could be impacted by problems with access to primary care under Medicaid insurance; and the corresponding lack of continuous access to asthma selfmanagement education in primary care setting and other community settings (including schools and childcare centers). Additionally, self-management of asthma could be greatly impacted by parent/family living constraints, including poor housing conditions, and the lack of knowledge for controlling exposure to environmental triggers for asthma (e.g., allergens and pollutants) in the home environment. These insights regarding the importance of "patient living, social, and community variables" in impacting self-management and asthma revisits are reinforced by the consistently low R-Square, i.e., $\leq 3 \%$ in all three regression models (see Table 4). These results essentially suggest that the "measurable" patient demographic variables used in the regression models (i.e., age, gender, race, and insurance), lack the potential to predict hospital revisit behavior for pediatric asthma, and that we may need to turn our attention to other aspects of a patient's life, for an explanation. Overall, study results (pre/post intervention) suggest that the challenge of high outpatient revisits for pediatric asthma may not be effectively addressed solely through a "hospital-based management intervention" to improve provider-parent communication of the AAP. Instead, it may require a "social and community-based intervention" involving a network of asthma stakeholders, including the state health department, primary care/school providers, clinical care providers, Community Health Workers (CHWs), and housing authorities, to address a complex set of socioeconomic, educational, and living environment constraints faced by asthma patients/families in the CHOG community.

Recent reports from the CDC National Asthma Control Program (NACP) lend further credence to the results and insights of this study. The NACP funds 34 states, the District of Columbia, and four non-governmental organizations to help them improve surveillance efforts, train health professionals, and educate individuals with asthma. According to the NACP, the biggest barrier to effective and sustainable asthma management and control is the lack of reimbursement for the four evidence-based asthma management services identified by the NAEPP: 1) Asthma self-management education in clinical, primary care, and non-clinical community settings; 2) Trigger reduction education (i.e., control of factors contributing to asthma severity, including assessment and modification of environmental triggers); 3) Assessment and monitoring; and 4) Pharmacotherapy. ${ }^{[1]}$ Reimbursements policies for all four services are known to vary widely across state Medicaid and private insurance plans. However, reimbursement for services (1) and (2), i.e., asthma self-management education and environmental trigger education by public and private insurers tends to be far less comprehensive compared to reimbursement for (3) and (4), i.e., assessment/monitoring and pharmacotherapy.

According to the NACP, state programs that have succeeded in improving self-management and reducing hospital encounters for asthma, have all strived for success in improving insurance reimbursement for asthma self-management education and environmental trigger education. For example, with funding support from the NACP, the Connecticut Department of Health developed an in-home child asthma program focusing on patient and family self-management education and recognition and elimination of environmental and other asthma triggers. A registered sanitarian conducts home visits to assess the home for triggers and recommends ways to reduce or eliminate them. A registered nurse, respiratory therapist, or certified asthma educator provides patients self-management education and reviews medications. The Department then formed a workgroup that met with Connecticut state legislators to share results of interventions and current research on cost savings or return on investment. Legislators supported reimbursement for preventive self-management patient education and connected Council members with Medicaid committees to provide input as restructuring of Connecticut Medicaid began. Similarly, the Maine Asthma Health Program provides one-on-one educational visits at its facility for patients and families, emphasizing the family's role in supporting asthma self-management skills. It also provides hands-on tools and educational sessions for providers in hospital and outpatient settings. The program successfully receives reimbursement from thirdparty payers including Medicaid through a facilities charge (S9441 - asthma education, non-physician provider, per session). The Massachusetts Asthma Control Program has focused on sustaining asthma clinical care, in particular home visits by $\mathrm{CHWs}$, through activities aimed at increasing the voluntary coverage by insurers. Several Massachusetts insurers cover CHW in-home asthma education and assessment, and Massachusetts Medicaid has also developed a bundled payment pilot for high-risk pediatric asthma patients.

Despite concerted efforts by NACP programs however, 
the CDC reports that asthma prevalence is at an all-time high, and continues to disproportionately affect specific demographic groups, including children, women, AfricanAmericans, and those reporting income below the federal poverty level. ${ }^{[1,28]}$ Asthma represents a huge public health burden in the state of GA in particular, with growing pressures for community-based approaches to intervention since there is no known medical cure. Approximately 297,000 children 0-17 years (12\%) and 600,000 (9\%) adults in the state have asthma, and, GA is noted to have significantly higher child asthma prevalence rates compared to U.S., $11 \%$ vs. $5.7 \%$ for the $0-4$ year group, and $15.4 \%$ vs. $10.4 \%$ for the 10-14 year group. ${ }^{[1,29]}$ Current policies for coverage for children in GA are silent on services provided by CHWs. In addition, asthma management services not provided in clinical settings are not reimbursed by the GA Families Care Management Organization. ${ }^{[26]}$ Additionally, minority and lowincome communities in GA continue to be plagued by environmental triggers (e.g., tobacco smoke, dust mites), due to factors beyond their control such as low-income housing and air pollution. ${ }^{[30]}$ CHWs are known to be at the core of asthma environmental trigger education. ${ }^{[27,31-33]}$ In view of the numerous recommendations from the $\mathrm{CDC}$ that communitylevel interventions improve asthma care in minority and low-income communities, the lack of reimbursement for these services in GA, may be posing a major barrier to both: 1) asthma management/control efforts, and 2 ) the provision of asthma services in clinical settings, due to lack of insurance. Several policy studies have recommended changes to state reimbursement systems for asthma services. The benchmark states of Massachusetts, Minnesota, and New York ${ }^{[34-36]}$ have all established modalities for asthma reimbursement for CHWs and other providers of asthma education, which in turn could be adopted in states like GA. ${ }^{[37-39]}$

\subsection{Future research avenues}

The above discussion provides a foundation for understanding the significance of this study. By itself, this study highlights the inefficacy of hospital-based efforts to improve provider-to-patient/family communication of the AAP, in the absence of broader community-and policy-level interventions to manage and control asthma. Also, while a majority of existing studies have focused on the management of "moderate-to-severe" asthma symptoms, this study serves to highlight a community that is fairly unique in seeking a substantial amount of hospital-based outpatient care for treating "low-to-moderate" asthma symptoms. ${ }^{[10]}$

According to the NACP, identifying the unique factors impacting self-management and revisits in each state or region is the first step to designing effective interventions for asthma management and control. ${ }^{[1]}$ As such, a key contribution of this study lies in its potential to generate timely future research for improving asthma self-management and reducing hospital revisits in in the CHOG community, and correspondingly, at the state and national levels. A natural extension of this study would be to explore the possibility of tracking and comparing "non-revisits", "revisits", and "high revisits" at CHOG, beyond their outpatient encounter over time, to gain a comprehensive understanding of "patient living, social, and community variables" impacting self-management and hospital revisits for pediatric asthma. A distinguishing feature of such a study would be its potential to identify "root causes" for hospital revisits from the patient's perspective. Results from such a study could be used to identify barriers to asthma self-management and causes for hospital revisits that are unique to the local community, which in turn could help to design appropriate interventions (at the hospital/organizational, community, and policy levels), to address these challenges. Such research in turn would have the potential to make substantial contribution to both the asthma services and asthma policy literatures, while also helping to address the substantial costs and public health burden of the disease at a national level.

On a related note, this study provides the basis for broadening the theoretical framework, i.e., for transitioning from a "hospital-based change management framework" to a "community-based socio-ecological framework". The socialecological model recognizes the interwoven relationship that exists between the individual and the environment with respect to disease management. ${ }^{[10]}$ While individuals are responsible for instituting and maintaining the lifestyle changes appropriate for optimal health, individual behavior is also influenced to a large extent by social, environmental, community norms, regulations and policies. The most effective approach to health behavior change therefore, may be a combination of individual/interpersonal (micro-level) and organizational/community/policy (macro-level) interventions.

\subsection{Practice implications}

In addition to providing policy implications, the results generate several implications for practice, including insights into the optimal role of hospital outpatient clinic providers and healthcare managers in promoting asthma self-management. Results indicate that efforts to effectively communicate the AAP in the hospital setting alone, may not be effective in promoting self-management and preventing hospital encounters for asthma. Instead, outpatient providers and managers may need to supplement these efforts by developing partnerships with asthma stakeholders in the community (e.g., primary care providers, schools, and child care centers), to increase 
access to asthma self-management education in community settings. Additionally, outpatient providers could become familiar with existing community resources for environmental trigger control education (e.g., those offered by local health departments or housing authorities), for providing timely and helpful "referrals" to families with asthma.

Additionally, asthma care providers based in academic health centers, could partner with health science educators on campus, e.g., those based in respiratory therapy or environmental health educational programs, to design and secure funding for community-based education efforts related to asthma selfmanagement and environmental trigger control education. For example, in Illinois, the Southern Illinois University at Edwardsville (SIUE) Medical Center partnered with the East Side Health District (Illinois Department of Public Health) to offer the Illinois Lead Environment Asthma Prevention Program (LEAPP), supported by the NACP. Children eligible for program services must have an asthma diagnosis or blood lead level of two micrograms per deciliter or greater. LEAPP assigns specialized nurses to conduct home and health assessments, provide patient education, and inform families about managing overall health. Medicaid provides reimbursement for the LEAPP program. SIUE bills Medicaid for the asthma portion, which includes asthma education and "spirometry" (diagnostic breathing exam). The East Side Heath District bills for lead-related services. The Asthma and Allergy Foundation of America donates supplies, such as mattress covers other materials. A grant to the East Side Heath District supplements the elimination of lead and pests. ${ }^{[1]}$

This study (at CHOG) serves as an example for how hospitals could leverage their own databases to gain insight into prominent community health needs, which in turn could be addressed through community partnerships. Similar efforts to collect and analyze data at the hospital level, for developing community-based interventions, have potential to either directly influence health policy (e.g., asthma reimbursement models) or indirectly effect policy change by supplementing efforts of key stakeholders (e.g., state advocacy groups for asthma prevention).

Last but not least, there are several incentives for hospitals to prioritize partnerships for community health promotion, in a new era of the Affordable Care Act. ${ }^{[40]}$ Aside from the immediate benefits of reduced clinic and ED overcrowding, improved clinic workflow, and reduced hassles with insurance companies (for reimbursing asthma services), there are many provider payment reform initiatives that are increasingly rewarding hospitals for community health promotion efforts (e.g., referrals to pulmonary rehabilitation services to prevent readmissions for congestive heart failure), and pe- nalizing costly adverse outcomes, like hospital readmissions and "preventable" complications. In 2010, as an extension of the American Hospital Association's Better Health Care roadmap for improving America's health care system, the Association's Long-Range Policy Committee focused on the "Wellness" pillar by identifying emerging, successful practices in community and employee health and wellness. The importance of this topic is evident in the critical role hospitals play in their communities, the financial case for creating a culture of health, the national set of public health goals found in Healthy People 2020, and the incentives to become accountable for overall population health found in the Affordable Care Act. ${ }^{[40]}$

\section{Conclusions}

In summary, both the national asthma management and treatment guidelines and the asthma services literature, have highlighted importance of the healthcare provider in promoting asthma self-management through effective communication of the AAP. On the other hand, the asthma policy literature has emphasized the need for broader community-and-policylevel interventions to address the challenge of asthma management and reduce the public health burden of asthma. This study highlights the inefficacy of hospital-based efforts to improve provider-to-patient/family communication of the AAP, in the absence of more holistic community-based initiatives to manage and control asthma. Indeed, a key inference from the study is that is that effective provider-to-patient/family communication of AAP in the hospital outpatient setting by itself, may only be the "short-end of the lever" (with low leverage) for impacting self-management and revisits for pediatric asthma. The CDC reports that communities that have succeeded with asthma management have strived for success in improving reimbursement for asthma self-management education and environmental trigger management. This study provides a foundation for conducting important future research on key barriers to asthma self-management and "root causes" for hospital revisits in the Augusta, GA community; research that could serve as a springboard for not only designing effective interventions to address these challenges in the local community, but also for influencing asthma reimbursement policy in GA and other states with similar reimbursement models. Such efforts in turn, could ultimately serve to improve asthma self-management, and reduce the public health burden of the disease at a national level.

\section{ACKNOWLEDGEMENTS}

The authors would like to thank the administrators, staff, and providers at the Children's Hospital of Georgia (CHOG), for their invaluable support in conducting the six-month survey of "Parent Understanding of the Childs's Asthma-Action 
Plan" in the inpatient and outpatient units of CHOG from July to December 2013. We would like to add special thanks to Dr. Andrew Mazzoli, Ms. Rebecca Douglas, Dr. Lind- say Blake, and Ms. Naomi Williams for their invaluable contributions in the developmental stages of this project.

\section{REFERENCES}

[1] Centers for Disease Control and Prevention (CDC). Asthma SelfManagement Education and Environmental Management: Approaches to Enhancing Reimbursement. National Asthma Control Program. 2013. Available from: http://www.cdc.gov/asthma/p dfs/Asthma_Reimbursement_Report.pdf

[2] Akinbami L. Asthma Prevalence, Health Care Use and Mortality: United States (2003-2005). CDC National Center for Health Statistics; 2011. Available from: http://www.cdc.gov/nchs/data/ nhsr/nhsr032.pdf [Retrieved May 2014].

[3] Bahadori K, Doyle-Waters MM, Marra C, et al. Economic burden of asthma: a systematic review. BMC pulmonary medicine. 2009; 9(1): 24. PMid: 19454036. http://dx.doi.org/10.1186/1471-246 6-9-24

[4] NAEPP. National Asthma Education and Prevention Program: Key Clinical Activities for Quality Asthma Care. 2007.

[5] Bhogal S, Zemek R, Ducharme FM. Written action plans for asthma in children (Review). Evidence-Based Child Health. 2007; 2: 553603. http://dx.doi.org/10.1002/ebch.131

[6] Jones M. Asthma Self-Management Education. Respiratory Care. 2008; 53(6): 778-786. PMid: 18501031

[7] The Joint Commission. Specification Manual for National Inpatient Quality Measures. 2012. Available from: http: //www.jointcommission.org/specifications_manual_fo r_national_hospital_inpatient_quality_measuresaspx [Retrieved May 2014].

[8] Asthma Research Council. Investing in Best Practices for Asthma. 2010.

[9] Thai A, George M. Review Article: The Effects of Health Literacy on Asthma Self-Management. Journal of Asthma and Allergy Education. 2010; 1(2): 50. http://dx.doi.org/10.1177/2150129710368 850

[10] Centers for Disease Control and Prevention (CDC). Economic Value of Home-Based, Multi-Trigger, Multicomponent Interventions with an Environmental Focus for Reducing Asthma Morbidity. A Community Guide Systematic Review. 2009.

[11] Centers for Disease Control and Prevention (CDC). Asthma in Georgia. National Asthma Control Program. 2008.

[12] GDPH. Georgia Data Summary: Child Asthma. Georgia Department of Public Health. 2013.

[13] Kuhlthau K, Bloom S, Van Cleave J, et al. Evidence for FamilyCentered Care for Children with Special Health Care Needs: A Systematic Review. Academic Pediatrics. 2011; 11(2): 136-143 PMid: 21396616. http://dx.doi.org/10.1016/j.acap. 2010 .12 .014

[14] Ring N, Malcolm C, Wyke S, et al. Promoting the use of Personal Asthma-Action Plans: A Systematic Review. Primary Care Respiratory Journal. 2007; 16(5): 271-283. PMid: 17710351. http: //dx.doi.org/10.3132/pcrj.2007.00049

[15] Misra-Hebert A, Isaacson J. Overcoming Health Care Disparities via Better Cross-Cultural Communication and Health Literacy. Cleveland Clinic Journal of Medicine. 2012; 79(20): 179-183. http: //dx.doi.org/10.3949/ccjm.79a.11006
[16] Schillinger D. Improving chronic disease care for populations with limited health literacy. Health literacy: a prescription to end confusion; 2004.

[17] Mangione-Smith R, Elliott M, McDonald L, et al. An Observational Study of Antibiotic Prescribing Behavior and the Hawthorne Effect. Health Services Research. 2002; 37(6): 1603-1623. PMid: 12546288. http://dx.doi.org/10.1111/1475-6773.10482

[18] Anderson A, McDaniel R. Managing Health Care Organizations: Where Professionalism Meets Complexity Science. Health Care Management Review. 2000; 25(1): 83-92. PMid: 10710732. http: //dx.doi.org/10.1097/00004010-200001000-00010

[19] Rangachari P. Knowledge Sharing Networks Related to Hospital Quality Measurement and Reporting. Health Care Management Review. 2008; 33(3): 253-263. PMid: 18580305. http://dx.doi.o $\mathrm{rg} / 10.1097 / 01$. HMR .0000324910.26896.91

[20] Rangachari P. Knowledge Sharing and Organizational Learning in the Context of Hospital Infection Prevention. Quality Management in Health Care. 2010; 19(1): 34-45. PMid: 20042932. http: //dx.doi.org/10.1097/QMH.0b013e3181ccbd1d

[21] Pronovost PJ, Berenholz SM, Goeschel CA, et al. Creating High Reliability in Health Care Organizations. Health Services Research. 2006; 41(4): 1599-1616. PMid: 16898981. http://dx.doi.org $/ 10.1111 / j .1475-6773.2006 .00567 . x$

[22] Pronovost PJ, Goeschel CA, Colantuoni E, et al. Sustaining Reductions in Catheter Related Bloodstream Infections in Michigan Intensive Care Units: Observational study. British Medical Journal. 2010; 44: 340-349. http://dx. doi.org/10.1136/bmj . c309

[23] Rangachari P, Madaio M, Rethemeyer RK, et al. The Evolution Of Knowledge Exchanges Enabling Successful Practice Change In Two Intensive Care Units. Health Care Management Review. Oct 22, 2013.

[24] Rangachari P, Madaio M, Rethemeyer RK, et al. Cumulative Impact of Top-Down Periodic Quality Improvement Communications on Infection Prevention Practices and Outcomes In Two Units. Health Care Management Review. Aug 12, 2014. PMid: 25120195.

[25] Fisher L, van Belle G. Biostatistics: A Methodology for the Health Sciences. New York, NY: Wiley and Sons; 1993.

[26] National Asthma Educator Certification Board. Asthma Coding Billing and Reimbursement for the State of Georgia. 2011.

[27] Martin M, Hernández O, Naureckas E, et al. Improving Asthma Research in an Inner-City Latino Neighborhood with Community Health Workers. Journal of Asthma. 2005; 42(10): 891-895. PMid: 16393730. http://dx.doi.org/10.1080/02770900500 371443

[28] Centers for Disease Control and Prevention (CDC). Vital Signs: Asthma in the US Growing Every Year. 2012.

[29] GDPH. Georgia Data Summary: Adult Asthma. Georgia Department of Public Health. 2013.

[30] GDPH. Environmental Health. 2010. Available from: http://dph. georgia.gov/environmental-health

[31] Joseph KE, Adams CD, Cottrell L, et al. Providing dust mite-proof covers improves adherence to dust mite control measures in children with mite allergy and asthma. Annals of Allergy, Asthma \& 
Immunology. 2003; 90(5): 550-553. http://dx.doi.org/10.10 16/S1081-1206(10)61849-2

[32] Takaro TK, Krieger JW, Song L. Effect of environmental interventions to reduce exposure to asthma triggers in homes of lowincome children in Seattle. Journal of Exposure Science and Environmental Epidemiology. 2004; 14: S133-S143. PMid: 15118754. http://dx.doi.org/10.1038/sj.jea. 7500367

[33] Medica Minnesota. Minnesota Health Insurance Plans. 2011. Available from: www .medica. com [Retrieved December 2011].

[34] MDPH. Massachusetts Department of Public Health. Strategic Plan for Asthma in Massachusetts 2009-2014. 2009. Available from: http://www.mass.gov/eohhs/docs/dph/com-health/ asthma/state-plan.pdf [Retrieved December 2012].

[35] NYS. New York State Office of Health Insurance Programs. Asthma and Diabetes Self-Management Training Services for Medicaid Beneficiaries. 2011.

[36] Freeman NC, Schneider D, McGarvey P. The Relationship of Health Insurance to the Diagnosis and Management of Asthma and Respiratory Problems in Children in Predominantly Hispanic Urban Commu- nity. American Journal of Public Health. 2003; 93: 1316-1320. PMid: 12893621. http://dx.doi.org/10.2105/AJPH.93.8.1316

[37] Halterman JS, Montes G, Shone LP, et al. The Impact of Health Insurance Gaps on Access to Care Among Children with Asthma in the U.S. Ambulatory Pediatrics. 2008; 8(1): 43-49. PMid: 18191781 http://dx.doi.org/10.1016/j.ambp.2007.10.005

[38] Georgiou A, Buchner DA, Ershoff DH, et al. The impact of a largescale population-based asthma management program on pediatric asthma patients and their caregivers. Annals of allergy, asthma \& immunology. 2003; 90(3): 308-315. http://dx.doi.org/10.10 16/S1081-1206(10)61799-1

[39] Laymon B, Shah G, Leep CJ, et al. The Proof's in the Partnerships: Are Affordable Care Act and Local Health Department Accreditation Practices Influencing Collaborative Partnerships in Community Health Assessment and Improvement Planning? Journal of Public Health Management and Practice. 2015; 21(1): 12-17. PMid: 25414951. http://dx.doi.org/10.1097/PHH.0000000 000000087

[40] Affordable Care Act. 2010. [Retrieved: December 2012]. 